\title{
Peer-assessment in the ESL classroom: a practical project
}

\author{
Carmen Maíz Arévalo \\ Facultad de Filología \\ Universidad Complutense de Madrid
}

Received: 21 May 2007 / Accepted: 12 July 2007

ISSN: $1697-7467$

\begin{abstract}
The Common European Framework is aimed at bringing the learner back to the centre of the teaching-learning process. As teachers, we should become helping tools intended to raise the learner's awareness of their own potential. Within this framework, self-assessment gains more importance that it has been usually given to. Quite surprisingly, however, peer-assessment ${ }^{1}$ is hardly ever mentioned in the $C E F$. This paper is aimed at exploring the use of peer-assessment in the ESL classroom while describing and analysing a three-month project.
\end{abstract}

Key words: peer-assessment, ESL teaching and learning.

RESUMEN: El Marco Común Europeo tiene como objetivo situar al estudiante en el centro del proceso de aprendizaje. Como profesores, deberíamos convertirnos en herramientas destinadas a despertar la conciencia del alumno sobre su propio potencial. En este marco, la auto-evaluación adquiere mayor importancia de la que se le ha dado normalmente. Sorprendentemente, sin embargo, la evaluación por pares apenas si es mencionada en el Marco Común Europeo. Este artículo pretende explorar el uso de la evaluación por pares en la clase de inglés como segunda lengua además de describir y analizar un proyecto práctico que ha tenido lugar durante tres meses.

Palabras clave: evaluación por pares, enseñanza y aprendizaje del inglés como segunda lengua.

\section{INTRODUCTION}

Creating a supportive, friendly environment in the ESL classroom is a basic requirement for the successful development of learners' acquisition of language. The first and most important function of language is communication and a friendly environment where students are willing to communicate with each other becomes an essential requirement. However, it is not always easy to create this atmosphere and its success depends on many external factors such as age difference, sex, learners' personality, general background and personal 'chemistry' between classroom.

${ }^{1}$ By the term peer-assessment, I am referring to the assessment carried out by the rest of learners in the 
students and teacher as well as among learners themselves. In my own experience, the presence of a high number of shy students in class can condition the whole atmosphere, which then becomes less interactive and involving. On the other hand, this has hardly been the case in my eleven years as a teacher and I can say that as teachers, we can always find the way to create a relaxed atmosphere in class and to become accessible and friendly figures that learners can approach without feeling intimidated and with whom they can reciprocally share their own experience ${ }^{2}$. As mentioned by Ovando et al. (2006: 157) an integral component of the teacher-student partnership is the affective dimension. As students and teachers gradually become friends, the classroom can become a place for sharing at the level of family or close community.

In order to develop this kind of relationship with students, it is important to listen to them attentively not only during the class but -more importantly -outside the class where we should keep on trying to communicate with them in the L2. In this situation, students are likely to be trying to perform 'real communication', e.g. by communicating to us that they will not be able to attend a future class, asking us questions about the lesson or simply by asking us to recommend them a book to read in the L2, to mention just a few examples ${ }^{3}$.

This is more than likely to result in a friendly atmosphere between students themselves, who on many occasions become friends outside the class too. The combination of all these elements leads to the development of a real communicative environment where students are willing to communicate among themselves and share their experiences. On this situation, however, it is important to make sure students do not use their L1 language by giving them useful tools in L2 which they can exploit in class.

In this environment, the use of peer-assessment can become an extremely useful tool to develop other classroom skills such as team working, co-operation strategies, pro-social skills and it will prepare students "for an increasing interdependent workplace" (Kagan, 1992). Furthermore, peer-assessment is not only a way of sharing experiences but also a way to involve students in their own learning experience. By assessing their classmates, students also learn to assess themselves in their future performances. Thus, students can learn to develop their own autonomy and a more critical point of view regarding their own performance. Finally, learners feel part of the whole assessment process, which is not exclusively carried out by the teacher as an authority figure but also by and for themselves.

${ }^{2}$ On one occasion, my students were performing a pairwork activity where they had to ask each other questions about their most embarrassing experiences. The objective of the activity was to practise the use of the simple past and feeling adjectives. One of the students then raised his hand and asked me "and how about you, teacher? We are all talking about our embarrassing experience but you aren't!'. I told them about once when I had had the most embarrassing falling in the middle of a museum. From that moment on, our relationship as a class improved significantly and they became more interested in communicating themselves. On that particular occasion, a quite monotonous pair-work activity turned into a real communicative activity where students felt really involved and motivated to talk in the L2. Mistake correction only took place after the activity had finished when we had a group discussion about their common mistakes.

${ }^{3}$ Another useful way to communicate with students and develop a friendly relationship is the use of email. I have found that students like writing e-mails to me in English, which I always reply in a friendly tone and without correcting their mistakes so that they do not feel their attempt to communicate has turned into an exercise or a test. 
Nevertheless, it is important to mention that peer assessment should not be carried out at the beginning of the course but once students are comfortable with their classmates and with the teacher in order to avoid ill-will among classmates. In other words, once students feel the classroom is a comfortable place where they can actually work on their learning with the help of their classmates and the teacher and not as an intimidating place where their performance is being constantly judged.

\section{Project description and objectives}

The present paper describes the use of peer-assessment in an L2 class at A2 level (Common European Framework) in combination with oral presentations by students which are assessed by the teacher and students too. The project had three phases:

(i) students prepared their presentations independently or in little groups -this was done outside the classroom as students considered more appropriate.

(ii) students did their presentations in class, followed by peer-assessment.

(iii) group discussion followed to check on the general assessment of the activity.

Regarding objectives, the present study has four main objectives:

(i) claim the role of peer-assessment in global assessment as an objective tool. This has been done by using double-assessment. In other words, all the presentations were evaluated both by the students themselves but also by the teacher and the final marks were compared ${ }^{4}$.

(ii) check the utility of peer-assessment as a useful tool to:

- encourage students' involvement in the learning and evaluation processes as active participants.

- motivate students while giving them a chance to be the centre of the class and share their topic of interest with the rest"-including the teacher.

- create a real communicative situation.

- consolidate social relationships in the class as well as team-working skills.

- help and reinforce teacher's assessment since "both parties benefit from discussing and performing assessment together" (Marsh et al., 2006: 167).

(iii) to check whether the type of peer-assessment used affected the final result of the assessment. There have been three types of peer-assessment in a continuum of formality:

a) informal oral peer-assessment.

b) semi-formal written questionnaire.

c) formal written questionnaire provided by the teacher.

(iv) to check whether peer-assessment was influenced by the type of presentation (either topic presentation or role play).

${ }^{4}$ In the case of students' marks, the procedure has been to add all of them up and then find the average mark, which was compared with the teacher's. 


\subsection{Phase One: preparation of the oral project}

An oral 'public' presentation was part of the students' global assessment and students were allowed to choose the topic they were most interested in, they were also allowed to do their presentations independently or in little groups as communicative role plays. The present project involved twenty university students ${ }^{5}$ who chose between two main types of presentation:

(a) topic presentation: students talked -individually or in pairs -about a topic of their interest using the structure of the reading texts and/or listenings that had been seen in class but adapted them to their own particular topic. The topics dealt with in class where either personal experiences or topics of interest.

(b) role play presentation: students prepared a role play based on structures and vocabulary they had seen in class but adapting them to their particular example. These always were in pairs or even in groups of three.

On the whole there was a total of nine presentations, three of each type. The following table sums up the type and content of the presentations students gave in class.

Figure 1. Types of presentation

\begin{tabular}{|l|l|l|}
\hline \multicolumn{2}{|c|}{ Topic presentation } & \multirow{2}{*}{ Role-play presentation } \\
\hline Personal experience & \multicolumn{1}{|c|}{ Topic of interest } \\
\hline An e-mail to a friend & Festivals in India & $\begin{array}{l}\text { Victoria Beckham goes } \\
\text { shopping }\end{array}$ \\
\hline My trip to Holland & Picasso's life and work & TV discussion - interview \\
\hline My hometown & Pit Doherty's life and music & $\begin{array}{l}\text { Some friends watching } \\
\text { television }\end{array}$ \\
\hline
\end{tabular}

As shown by figure 1, the presentations at this level mostly deal with the same types of topic, all of them part of the "can-do statements" at the A2 level of the Common European Framework:

- people's profile

- travelling experiences

- place descriptions

- exchange of goods and services

- interviews

- everyday conversation

\subsection{Phase Two: presentation and peer-assessment}

Students were informed that they had to give a presentation in front of their classmates on the very first day of class. However, the actual presentations did not take place until the

${ }^{5}$ It is important to mention that students came from different backgrounds and studied different degrees, showing different types of interests, which made the classroom a place to share different experiences and get enriched. 
last term when the atmosphere was much more relaxed and students knew each other -and their teacher -quite well. These presentations were allowed to take from five to ten minutes and students were asked to prepare some follow-up questions for their classmates but their classmates were also free to ask them any question they wanted to; a common question was 'why have you chosen this topic?' Error correction only took place after all the interventions and it was never too personal but applied to the whole group in order to avoid students' embarrassment. As for peer-assessment, it was carried out in three different ways in a continuum from more to less "formal":

(a) oral and informal peer-assessment: after the presentation and the follow-up questions, students were asked if they had liked the presentation and why. They also discussed whether they had been able to understand everything and enjoyed their classmates' performance. Likewise, the 'performers' were asked how they had felt while doing their presentation -for many of them, it was the first time they had to talk 'in public' in the L2 and whether they thought they had learned something positive out of the experience.

(b) using a semi-formal written questionnaire: students were asked to write on a piece of paper why they had liked (or not) the presentation and any other comments they thought could be relevant. They were also asked to give their classmates a mark from one to ten. This questionnaire was also anonymous.

(c) using a formal written questionnaire: after the presentation and the follow-up questions, students were asked to fill in a brief questionnaire provided by the teacher (see appendix I). The questionnaire was always anonymous and handed out to the teacher at its completion.

The nine presentations were peer-assessed in one of the three different ways. In order to check whether the type of presentation could have any influence on the assessment, I tried to combine the type of presentation with the types of peer-assessment. Figure 2 sums it up:

Figure 2. Types of peer-assessment and types of presentation

\begin{tabular}{|l|l|l|l|l|l|}
\hline \multicolumn{1}{|c|}{$\begin{array}{c}\text { Personal } \\
\text { experience }\end{array}$} & \multicolumn{1}{|c|}{ PA } & \multicolumn{1}{|c|}{$\begin{array}{c}\text { Topic of } \\
\text { interest }\end{array}$} & PA & \multicolumn{1}{|c|}{$\begin{array}{c}\text { Role-play } \\
\text { presentation }\end{array}$} & PA \\
\hline $\begin{array}{l}\text { An e-mail to a } \\
\text { friend }\end{array}$ & Formal & $\begin{array}{l}\text { Festivals in } \\
\text { India }\end{array}$ & Formal & $\begin{array}{l}\text { Victoria Beckham } \\
\text { goes shopping }\end{array}$ & Informal, oral \\
\hline $\begin{array}{l}\text { My trip to } \\
\text { Holland }\end{array}$ & Semi-formal & $\begin{array}{l}\text { Picasso's life } \\
\text { and work }\end{array}$ & $\begin{array}{l}\text { Informal, } \\
\text { oral }\end{array}$ & $\begin{array}{l}\text { TV discussion - } \\
\text { interview }\end{array}$ & Semi-formal \\
\hline My hometown & Semi-formal & $\begin{array}{l}\text { Pit Doherty's } \\
\text { profile }\end{array}$ & $\begin{array}{l}\text { Informal, } \\
\text { oral }\end{array}$ & $\begin{array}{l}\text { Some friends } \\
\text { watching TV }\end{array}$ & Formal \\
\hline
\end{tabular}

Each of the techniques used for peer-assessment has their own pros and cons; in the first case, students had a tendency to be over-positive in their assessment of their classmates' performance since it was all carried out in front of them and they tried not to embarrass them if they had not been very good. On the other hand, informal peer-assessment frequently led 
to further follow-up questions -and thus to 'real communication' and it always motivated students to be better in their future performances so as to be liked and positively assessed by their peers. As for the use of written peer-assessment, it has the main advantage of being anonymous, which allows students to be more objective and confident to express their true opinion about their classmates' performance. Written questionnaires are also a more convenient way to keep good record of students' opinions. As for semi-formal questionnaires, students were given the chance to "speak their minds" without feeling the pressure of having to do so in front of all their classmates -including the ones giving the presentation. On some occasions, however, there were students -albeit a few- who forgot to give a mark or did not explicitly give any reasons why they had liked the presentation or not. The most formal questionnaire was also anonymous and prepared by the teacher (see appendix 1). It tried to include both open and closed questions. Thus, students were also asked to give reasons why they had liked/not liked the performance or why they had/had not understood their classmates' presentation apart from other closed questions concerning their classmates' use of English. Being more controlled, students were forced to pay closer attention to different aspects of their classmates' presentation -i.e. both contents and language, as opposed to the semi-formal questionnaire where they were free to write whatever they thought. The main disadvantage of formal questionnaires is that they took slightly longer to fill in and some students were somehow reluctant to do so.

\subsection{Phase Three: final assessment of the whole project}

At the end of the course, students were all given a little written report of their global performance and final mark with the teacher's and their classmates' global views. There was also a final group assessment where their whole experience of the project could be discussed. This was orally done in class but students were asked to be objective and honest. Their comments show that they were quite objective since they were not totally positive. In fact, most of them acknowledged that they felt uncomfortable when having to assess their classmates because it implied too much responsibility but that they had tried to be objective. Some of them even admitted that they had deliberately ignored the last question ("give a mark") specially in the semi-formal questionnaires.

Positive comments were mainly aimed at the presentations themselves. Students commented that they had enjoyed both preparing and delivering the presentations, even if they were initially anxious or nervous about speaking in public. They felt it had been a very positive experience since it had allowed them to use English in a real communicative situation, i.e. they had had the chance of speaking to their classmates about their favourite topics or about a personal experience. Listening to other students' presentations was also positively valued since they considered it was a more interactive experience and a good way to build up group's unity and friendship, especially in those cases where students had had to work together to prepare their common presentation. Besides, all the activities were carried out in English, which gave them the feeling that they were using the language in a "real" situation. 


\section{Data analysis}

As already mentioned in the previous section, the project involved twenty students who carried out nine oral presentations either individually or in little groups of two or three students. As for the number of written questionnaires, forty questionnaires were semi-formal and forty-one were formal. In the following section, we shall consider exclusively written questionnaires (both semi-formal and formal) since, quite unluckily, oral assessment in class proved to be too "superficial" and although it led to real communication it did not really assess the students giving the presentation. In fact, the rest of the classmates always agreed that the presentation had been very good and interesting.

\subsection{Semi-formal questionnaires}

Students were asked to write anonymously on a piece of paper what they objectively thought about their classmates' presentation. They had to explain if they had liked the presentation or not and give reasons in one or two sentences. They were also asked to give a mark from one to ten, although some of them ignored this request for the reasons already mentioned above. As opposed to informal peer-assessment, students were much more objective and tried to justify why they considered their classmates' presentation good or bad. Comments included both contents and language. These were the most common assessments:

\section{Contents assessment}

Positive: original, entertaining, interesting, funny, real life, personal, well-structured.

Negative: boring topic, bad story, too nervous.

\section{Language assessment}

Positive: easy to understand, fluent, good pronunciation and accent, clear.

Negative: bad pronunciation, not fluent, hesitations.

As can be observed, students' comments include both positive and negative aspects. Quite significantly, however, they are objective enough to make a difference between contents and language. In other words, even in those cases when they found the topic boring, they acknowledged that the use of English was correct and vice versa. On the whole, they were also very balanced when commenting on content and language and although their comments were slightly more frequently targeted at contents - especially in the case of role-plays -they also included comments about use of English, accent and pronunciation. Quite significantly, there were also comments of self-assessment rather than peer-assessment. A very frequent comment was "I liked it because I could understand everything / it was easy for me to understand". This proves that this kind of activities, far from being time-consuming as some teachers think, can powerfully contribute to learner's autonomy and raise their awareness. As for the kind of presentation, i.e. whether it is a role-play or a topic presentation, no significant differences were found. 
Together with their comments, students were also asked to give a numeric mark to their classmates from one to ten. The average mark was then contrasted with the mark given by the teacher to check whether students were overrating or underrating their classmates. The following table sums up the results of this double-assessment:

Figure 3. Double assessment in semi-formal questionnaires

\begin{tabular}{|c|c|}
\hline Students' mark & $\begin{array}{c}\text { Teacher's } \\
\text { mark }\end{array}$ \\
\hline 7 & 6.5 \\
\hline 8.2 & 8.5 \\
\hline 7 & 7.5 \\
\hline
\end{tabular}

As shown by results, students' marks were very accurate and practically equivalent to those given by the teacher. One significant drawback, however, was that in those cases where more than one student was involved in the presentation, students gave a global mark and did not refine their assessment as opposed to the teacher, who gave individual marks to each of the students involved in the same presentation. In future projects, this will be a serious aspect to take into consideration and students will have to be trained to evaluate groups in a more individual way.

\subsection{Formal questionnaires (see appendix one)}

This questionnaire included different types of questions aimed at different objectives. Thus, there were open questions targeted at eliciting the students' objective opinion (question 1) and self-assessment (question 2). More closed questions with multiple choice answers were also included to focus on the assessment of the use of English (questions 3 and 4). Finally, students were also asked to give a numeric score from one to ten. In this case and since it was a more formal questionnaire, students could not avoid their responsibility and felt they had to give an answer.

The analysis of the data reveals that students are very objective when answering this type of questionnaires. They can also separate the comments on language from those on content, even in those cases where one of these two aspects is negatively assessed. However, this kind of questionnaire seems to determine the answer to the first open question "I liked / didn't like the presentation because..." In fact, the majority of comments here focus on contents -and not language -as opposed to semi-formal questionnaires, where the results were much more balanced. This is even more evident when the type of presentation involves a role-play. Of the forty-one formal questionnaires analysed, only thirteen include some comment on language in the first question whereas the rest prefer making comments on content ("it was original, funny, interesting, entertaining" and so on). Some assessments on use of English are, however, very significant. On several occasions, students write that they have liked the presentation because "it reminded me of grammar and vocabulary we had seen in class before" or, as in semi-formal questionnaires, because "they could understand the classmates' English easily". As for the marks, the results are similar but slightly better. Students seem to be "more generous" when filling in formal questionnaires than when they 
are free to write what they really think. Another possible explanation can be related to the fact that in this type of questionnaire, students are more aware of their classmates' use of English thanks to questions 3 and 4. Thus, when they think their classmate has a good accent or is fluent, they tend to overrate their mark, which did not happen in semi-formal questionnaires, where results were much more balanced.

\section{Figure 4. Double assessment in formal questionnaires}

\begin{tabular}{|c|c|}
\hline Students' mark & $\begin{array}{c}\text { Teacher's } \\
\text { mark }\end{array}$ \\
\hline 6.8 & 6 \\
\hline 7.8 & 6.5 \\
\hline 8.2 & 8.5 \\
\hline
\end{tabular}

Again, we face the same problem regarding groups; students give a global mark whereas the teacher gives an individual mark to the different members of the group. As in the previous case, future formal questionnaires will have to be developed including different comments/ marks for each of the members of the group.

\section{Conclusions}

The present study had four main objectives or questions to answer. Firstly, the analysis has shown that peer-assessment can have an important role in global assessment since it can help and reinforce teacher's assessment. This has been particularly useful in the case of semiformal questionnaires where the final mark given by the teacher coincided in most cases with the average mark given by the different students. As argued in the Common European Framework (2001: 191) "self-assessment can be an effective complement to tests and teacher assessment". On other occasions, where the teacher hesitated between two possible results, the marks given by other classmates has helped to take a final -and hopefully more objective -decision. Double assessment has helped seen whether the students' marks were "objective". This was specially so in the case of semi-formal questionnaires, as has already been discussed in the previous section.

Regarding the second objective or the utility of peer-assessment as a useful tool in the classroom, both the presentations and the subsequent peer-assessment has helped involve students in their learning and evaluation process as learning participants. Although many students have responded negatively to the responsibility of assessing their partners -which they consider as a decision to be taken exclusively by the teacher -others have shown their approval of the activity. On the whole, they have all enjoyed preparing their presentations and having the chance to use their English communicatively in front of their classmates, which has been very motivating for them. This has been especially patent in the case of many roleplays, where both the students performing their "play" and the audience (including the teacher) had a very rewarding and motivating experience. Informal peer-assessment has also proved to be a good way to create a real communicative situation and once students could overcome their shyness, they felt confident enough to pose real questions to their partners, especially 
in those cases where topic presentations were involved (either personal experiences or topics of interest). Peer-assessment has also proved to be a useful tool to consolidate social relationships in the class as well as team-working skills. In fact, this was one of the most frequent comments that students made when asked to evaluate the whole experience. They felt they had become "more than classmates" and had enjoyed working on their English with their new friends. They also explained that the whole experience had helped to create a more relaxed atmosphere in the class and they felt closer to the teacher than they had felt with other teachers who did not involve them so actively.

In the third place, it has been confirmed that the type of peer-assessment does affect the final result of the assessment. Thus, whereas informal peer-assessment has proved useful for eliciting real communicative activities, it has proved quite fruitless for objective assessment, since students did not feel confident enough to criticise their partners in public and only made positive comments. Written assessment, on the other hand, has been very objective given the fact that it was anonymous and students did not feel the pressure of their classmates knowing what they really thought of their presentation. However, whereas formal assessment has resulted in a very controlled evaluation where students were highly conditioned by the order and type of questions given by the teacher, semi-formal questionnaires have been the most efficient way thanks to their objectiveness and their balanced answers. In other words, when left totally free, students were much more able to be objective and make comments both of their classmates' language and contents besides giving them a much more objective mark. In the case of more controlled questionnaires, however, students tended to overrate their partners in their numeric score and to base their (dis)like of presentations almost exclusively on their content. It has also been confirmed that they type of presentation has a partial influence on peer-assessment, especially in the case of formal assessment. In the case of semi-formal questionnaires, it has been seen that there are no significant differences even when different types of presentation are involved.

In conclusion, peer-assessment has proved to be an extremely useful tool worth exploring in detail in the ESL classroom for its high potential as a motivating and integrating force. Despite the actual difficulties to train students to become more responsible for their learning, once they learn how to do so, they become objective evaluators who can help other classmates, themselves and their teacher.

\section{Bibliography}

Council for Cultural Co-operation (eds.) (2001). Common European Framework of Reference for Languages: Learning, Teaching, Assessment. Cambridge: Cambridge University Press.

Hamayan, E. V. (1993). Current trends in ESL curriculum. In English as a second language curriculum resource handbook: a practical guide for K-12 ESL programs. Millwood, NY: Kraus International.

Igoa, C. (1995). The inner world of the immigrant child. New York: St. Martin's.

Kagan, S. (1986). Cooperative learning and sociocultural factors in schooling. In Beyond language: Social and cultural factors in schooling language minority students. Sacramento, CA: California Department of Education.

Kagan, S. (1992). Cooperative learning. San Juan Capistrano, CA: Kagan Cooperative Learning. 
Maíz, C. \& C. Melchor (2005). Interaction and production in oral projects at two different but close levels: the role of personal motivation. In Panorama de las lenguas en la enseñanza superior. IV Congreso de ACLES. Madrid: Universidad Antonio de Nebrija (in press).

Marsh, D., B. Marsland \& K. Stenberg (2006). Integrating competences for working life. Finland: University of Jyvälskylä.

Oskarsson, M. (1980). Approaches to self-assessment in foreign language learning. Oxford: Pergamon. 


\section{APPENDIX I: \\ Questionnaire for peer-assessment \\ (to be carried out anonymously after presentations)}

1. I liked / didn't like the presentation because

2. I could understand
a. everything
b. almost everything
c. almost nothing
d. nothing

because

3. In my opinion, my classmate(s)'s general use of English was
a. excellent
b. good
c. poor
d. very good
e. ok
f. very poor

4. What I liked most about my classmate(s)'s English was (you can choose more than one option)
a. their accent
c. their fluency
b. their pronunciation
d. their use of clear vocabulary and structures

5. If I had to give my classmate(s) a score from ONE to TEN, I would give them a 